\title{
ANALISIS PENDAPATAN NELAYAN DAN FAKTOR YANG MEMPENGARUHI DI HILIR SUNGAI BENGAWAN SOLO KAB LAMONGAN
}

\author{
Muntalim*,Tri Wahyudi* \\ *Fakultas Perikanan Universitas Islam Lamongan \\ Jl. Veteran No. 53 A Lamongan Phone /Fax 0322_324706
}

\begin{abstract}
ABSTRAK
Hilir Sungai Bengawan Solo yang berada di Kabupaten Lamongan memberikan kontribusi dalam kesejahteran masyarakat daerah aliran sungai khususnya nelayan. Pendapatan nelayan yang tidak menentu menyebabkan perlunya kajian analisis pendapatan nelayan dan faktor yang mempengaruhi guna mewujudkan kesejahteraan masyarakat. Metode penelitian ini menggunakan metode deskriptif kuantitatif. Penelitian ini dilaksanakan pada bulan Mei - Juni 2017 pada empat stasiun di Kab Lamongan. Pengambilan data secara purposive sampling dengan cara kuisioner, wawancara serta observasi pada objek penelitian yaitu nelayan. Pengambilan variabel data primer pendapatan nelayan diantaranya umur, modal, teknologi serta cuaca. Data yang didapat akan di analisa dengan uji $\mathrm{F}$ dan $\mathrm{T}$ untuk mengetahui pengaruh variabel tersebut. Hasil penelitian menunjukkan persamaan model pendapatan di Hilir Sungai Bengawan Solo adalah Y $=999769,759+0,940$ X1 /Modal) 14646,928 X2/ Teknologi + (-8021,087) X3/Cuaca. Faktor - faktor yang mempengaruhi secara signifikan pendapatan nelayan di hilir Sungai Bengawan Solo kab Lamongan adalah modal sedangkan yang berpengaruh secara simultan ialah modal, teknologi dan cuaca.
\end{abstract}

Kata Kunci : Hilir Sungai Bengawan Solo, analisis pendapatan. nelayan

\section{PENDAHULUAN}

Sumber daya alam yang terdapat pada perairan Sungai Bengawan Solo memberikan kontribusi penting di sektor perikanan, salah satunya perikanan tangkap. Menurut Dahen (2016), sumberdaya perikanan secara potesial dapat dimanfaatkan untuk meningkatkan taraf hidup masyarakat nelayan, namun pada kenyataannya masih cukup banyak nelayan belum dapat meningkatkan hasil tangkapannya. Pendapatan usaha tangkap nelayan sangat berbeda dengan jenis usaha lainnya, sepeti pedagang atau petani yang dapat mengkalkulasikan serta memprediksi keuntungan setiap bulannya, hal ini dikarenakan tingginya ketidakpastian (uncertainty) serta bersifat spekulatif dan fluktatif ( Wahyono et. al, 2001 dan Kusnadi 2007 dalam Rahim 2011).

Fenomena kesejahteraan nelayan yang rendah merupakan permasalahan yang sering terjadi, terutama nelayan tradisional (Rahim, 2011). Pengelolaan perikanan tangkap di Sungai Bengawan Solo yang tepat serta lestari memerlukan suatu data /informasi mengenai faktor mempengaruhi pendapatan nelayan. Oleh karena itu perlunya kajian analisis pendapatan nelayan dan faktor yang mempengaruhinya di hilir Sungai Bengawan Solo Kabupaten Lamongan. 


\section{METODOLOGI}

Metode penelitian ini menggunakan metode deskriptif kuantitatif. Penelitian ini dilaksanakan pada bulan Mei - Juni 2017 pada empat stasiun di Kab Lamongan. Pengambilan data secara purposive sampling dengan cara kuisioner, wawancara serta observasi pada objek penelitian yaitu nelayan. Pengambilan variabel data primer pendapatan nelayan diantaranya umur, modal, teknologi serta cuaca.

\section{Analisa Data}

Metode analisis yang digunakan dalam mengetahui variabel-variabel yang berpengaruh pada pendapatan usaha nelayan menggunakan persamaan regresi linear berganda sebagai berikut:

$\mathrm{Y}=\mathrm{a}+\mathrm{b} 1 \times 1+\mathrm{b} 2 \times 2+\mathrm{b} 3 \times 3+\mathrm{e}$

Dimana :

$$
\begin{array}{ll}
\mathrm{Y} & =\text { Pendapatan } \\
\mathrm{A} & =\text { Konstanta } \\
\mathrm{X} 1 & =\text { Modal } \\
\mathrm{X} 2 & =\text { Teknologi } \\
\mathrm{X} 3 & =\text { Cuaca } \\
\mathrm{b} 1 & =\text { koefisien regresi untuk variabel Modal } \\
\mathrm{b} 2 & =\text { koefisien regresi untuk variabel } \\
& \text { teknologi } \\
\mathrm{b} 3 & =\text { Koefisien regresi untuk variabel Cuaca } \\
\mathrm{e} & =
\end{array}
$$

Analisa data dilanjutkan dengan uji $\mathrm{F}$ yang dimaksud untuk mengetahui pengaruh modal, teknologi dan cuaca terhadap variabel dependen yaitu pendapatan nelayan. Kaidah pengujian signifikasi : jika $\mathrm{f}$ hitung $\geq \mathrm{f}$ tabel, maka tolak Ho artinya variabel tersebut berpengaruh signifikan dan jika $f$ hitung $\leq f$ tabel. maka tolak Ho artinya variabel tersebut berpengaruh signifikan dan jika $f$ hitung $\leq \mathrm{f}$ tabel maka terima Ho atau tidak signifikan. Taraf signifikasi a:0,05.

\section{HASIL DAN PEMBAHASAN}

\section{Karakeristik Nelayan}

Karakteristik tingkat pendidikan nelayan di hilir Sungai Bengawan Solo Kab. Lamongan dari 50 responden bervariasi dari Tingkat Sekolah Dasar (SD) sampai Sekolah Menengah Atas (SMA) dengan urutan presentasi di tingkat SD (54\%), SMP (30\%) dan SMA (16\%). Sedangkan karakteristik nelayan berdasarkan usia berkisar 18-45 tahun dengan urutan presentasi umur berkisar 25 - 35 sebesar $46 \%$, umur $35-45$ sebesar $36 \%$ dan umur $16-25$ sebesar $18 \%$.

\section{Modal dan Pendapatan Nelayan}

Nelayan di hilir Sungai Bengawan Solo Kab Lamongan terdiri dari nelayan pancing, jala dan jaring. Pendapatan usaha tangkap nelayan di Hilir Sungai Bengawan Solo berkisar antara Rp. 1.035.000, - Rp. 2.190.000,-. /bulan. Modal usaha nelayan di Hilir Sungai dari 50 responden di dapatkan modal rata-rata nelayan pancing $\mathrm{Rp}$. 130.000,-; nelayan jala Rp. 450.000,- dan nelayan jaring Rp 1.000.000,-.

\section{Analisa pendapatan nelayan}

Berdasarkan hasil perhitungan estimasi maka didapatkan model persamaan pendapatan nelayan di Hilir Sungai Bengawan Solo Kabupaten Lamongan sebagai berikut : 


$$
Y=999769,759+0,940 X 1+14646,928 X 2+(-8021,087) X 3
$$

Dimana $: \mathrm{Y}=$ Pendapatan, $\mathrm{X} 2=$ Teknologi, $\mathrm{X} 1=$ Modal $\quad, \mathrm{X} 3=$ Cuaca

Hipotesis 1, persamaan antara modal (X1) terhadap pendapatan $(\mathrm{Y})$ dengan nilai koefisien regresi modal sebesar 0,94 apabila ada kenaikan modal 1 unit maka akan ada peningkatan pendapatan sebesar 0,94. Jika dari hasil uji $t$ hitung sebesar 9,185 > t tabel 2,012 maka tolak Ho dan terima $\mathrm{H} 1$ yang berarti terdapat pengaruh signifikan dari modal terhadap pendapatan.

Hipotesis 2, persamaan antara teknologi terhadap pendapatan $(\mathrm{Y})$ dengan nilai koefisien regresi teknologi sebesar 14646,9 apabila ada kenaikan modal 1 unit maka akan ada peningkatan pendapatan sebesar 14646,9. Jika dari hasil uji $\mathrm{t}$ hitung sebesar $-0,834<\mathrm{t}$ tabel 2,012 maka tolak H1 dan terima Ho yang berarti tidak terdapat pengaruh signifikan dari teknologi terhadap pendapatan.

Hipotesis 3, persamaan antara (X3) cuaca terhadap pendapatan $(\mathrm{Y})$ dengan nilai koefisien regresi cuaca sebesar -8021,1 apabila ada kenaikan modal 1 unit maka akan ada peningkatan pendapatan sebesar -8021,1. Jika dari hasil uji t hitung sebesar $-0,5<\mathrm{t}$ tabel 2,012 maka tolak H1 dan terima Ho yang berarti tidak terdapat pengaruh dari cuaca terhadap pendapatan.

Nilai R square sebesar 0,648 yang artinya $64,8 \%$ perubahan pada vaiabel dependen (pendapatan) dapat dijelaskan oleh variabel independen (modal, teknologi, cuaca), sedangkan sisanya sebesar $35,2 \%$ dipengaruhi oleh variabel lain.
Nilai Uji F pun pada penelitian ini adalah F hitung sebesar 28,2 dan F tabel sebesar 2,41 sehingga $\mathrm{F}$ hitung $>\mathrm{F}$ tabel yang artinya Tolak Ho dan terima H1. Dengan demikian dapat dikatakan bahwa modal, teknologi dan cuaca secara simultan berpengaruh terhadap pendapatan nelayan di hilir Sungai Bengawan Solo Kab Lamongan.

\section{KESIMPULAN}

Analisis pendapatan nelayan di hilir Sungai Bengawan Solo adalah $\mathrm{Y}=999769,759$ + 0,940 X(Modal $)+14646,928 \times($ Teknologi $)+$ $(-8021,087) \mathrm{X}(\mathrm{Cuaca})$. Faktor - faktor yang mempengaruhi secara signifikan pendapatan nelayan di hilir Sungai Bengawan Solo kab Lamongan adalah modal sedangkan yang berpengaruh secara simultan ialah modal, teknologi dan cuaca.

\section{DAFTAR PUSTAKA}

Dahen, L D. 2016. Analisis Pendapatan Nelayan Pemilik Payang Di Kecamatan Koto Tangah Kota Padang. Journal of economic and Economic Education (ECONOMICA) 5 (1): 47-57

Rahim , A. 2011. Analisis Pendapatan Usaha Tangkap Nelayan dan Faktor-faktor yang Mempengaruhinya di Wilayah Pesisir Pantai Sulawesi Selatan. Jurnal Sosek KP 6 (2): $235-247$ 